\title{
Positive Integer Data Type
}

National Cancer Institute

\section{Source}

National Cancer Institute. Positive Integer Data Type. NCI Thesaurus. Code C95680.

A data type comprised of numbers with no fractional part that are constrained to positive numbers only. 